\title{
PEMBEDONGAN BERPENGARUH TERHADAP PENURUNAN TINGKAT NYERI PADA BAYI YANG DILAKUKAN TINDAKAN INVASIF AMBIL DARAH
}

\author{
Yusi Sofiyah $^{1}$, Anne Rosliana ${ }^{2}$, Eli Lusiani ${ }^{3}$ \\ 1,3) Sekolah Tinggi Ilmu Kesehatan 'Aisyiyah Bandung \\ ${ }^{2)}$ Perawat Ruang Kebidanan RSUD Al Ihsan Provinsi Jawa Barat \\ ovieys@gmail.com
}

\begin{abstract}
ABSTRAK
Bayi baru lahir akan mendapatkan beberapa kali tindakan invasif, sehingga bayi akan memiliki pengalaman nyeri. Bayi akan mengalami ketidaknyamanan akibat nyeri yang dapat diobservasi melalui tangisan. Pembedongan adalah salah satu cara yang dapat dilakukan untuk menenangkan bayi. Tujuan penelitian adalah mengidentifikasi pengaruh pembedongan terhadap penurunan tingkat nyeri pada bayi yang dilakukan tindakan invasif ambil darah. Dengan menggunakan desain quasi eksperimental dengan teknik post test with control group, terhadap 36 bayi, didapatkan bahwa tingkat nyeri pada kelompok intervensi lebih rendah dibandingkan kelompok kontrol. Hasil uji statistik dengan uji Mann-Whitney yang telah dilakukan didapatkan hasil p-Value $0,000(\alpha=0,05)$ sehingga terdapat pengaruh pembedongan terhadap penurunan tingkat nyeri pada bayi yang dilakukan tindakan invasif ambil darah.Pembedongan sebagai salah satu intervensi nonfarmakologi yang efektif dan efisien untuk mengurangi nyeri pada bayi saat dilakukan tindakan invasif ambil darah.
\end{abstract}

Kata kunci : bayi, pembedongan, tingkat nyeri, tindakan invasif ambil darah

\section{Abstract}

Newborns will get several invasive actions, the baby will have pain experience. Babies will experience discomfort due to pain that can be observed through crying. Swaddling is one way that can be done to calm the baby. The purpose of this study was to identify the effect of surgery on reducing the level of pain in infants undergoing invasive blood-taking measures. Using a quasi-experimental design with a post-test with a control group technique, for 36 infants, it was found that the level of pain in the intervention group was lower than the control group. The results of the statistical tests with the Mann-Whitney test that have been done have obtained the $p$-Value of $0.000(\alpha=0.05)$. So there is the effect of swaddling on the reduction in pain levels in infants who take invasive blood-taking measures. Swaddling as one of the effective and efficient non-pharmacological interventions to reduce pain in infants during invasive blood-taking measures.

Keyword: infants, level of pain, invasive to take blood, swaddling 


\section{PENDAHULUAN}

Selama periode neonatal, bayi baru lahir menyesuaikan diri dengan lingkungan dengan perubahan biokimia dan fisiologis yang melibatkan semua sistem tubuh (Pappas \& Walker, 2010). Selama proses adaptasi ke lingkungan ekstrauterin, bayi baru lahir yang sehat menjalani intervensi medis seperti vaksinasi hepatitis B, injeksi vitamin $\mathrm{K}$, pemantauan kadar gula darah, dan skrining untuk bilirubin atau penyakit metabolik (Krishnan, 2013). Pengambilan darah vena pada bayi menimbulkan pengalaman nyeri, walaupun bayi tidak menunjukkan pengalaman nyeri yang dialami pada orang dewasa, namun hal tersebut dapat dilihat dari respons fisiologis dan perilaku bayi, bahwa mereka merespons terhadap nyeri (Kenner \& Lott, 2014). Kondisi distres ini ditunjukkan bayi neonatus dengan tidak stabilnya tekanan darah, penurunan saturasi oksigen, telapak tangan yang berkeringat, peningkatan tekanan intra kranial, perubahan hormonal dan perubahan metabolisme (Johnston et al., 2011).

Rangsangan nyeri yang ditimbulkan pada prosedur pengambilan darah, sering kali diabaikan oleh petugas kesehatan (Ball et al., 2010). Menurut Hockenberry dan Wilson (2009) bayi yang dirawat di rumah sakit akan mengalami hospitalisasi, diantaranya adalah terganggunya pembentukan rasa percaya, penurunan kontrol diri dan nyeri. Dalam sebuah penelitian yang dilakukan oleh Kusumaningsih (2016) menjelaskan bahwa selama bayi dirawat di rumah sakit, bayi akan mendapatkan tindakan invasif yang menimbulkan nyeri. Beheshtipoor, Memarizadeh, Hashemi, Porarian, dan Rambod (2014) mengatakan jika bayi mengalami nyeri dan ketidaknyamanan karena pengambilan darah vena yang berlangsung lama, bayi akan mengalami keterlambatan perkembangan, baik itu bahasa, motorik, kognitif, dan memori.

Bayi yang mengalami nyeri akan ditemukan tanda dan gejala ketika bayi merasakan nyeri menangis lebih keras, melengking dan akan berlangsung lebih lama dari biasanya (Harrison et al., 2017). Respons bayi terhadap nyeri dapat dilihat dari raut wajah bayi yang meringis, membuka mulut, mengerutkan dahi dan penekanan pada mata. Postur tubuh bayi akan lebih tegang dan kaku disertai dengan gerakan kaki dan tangan keluar masuk, sehingga bayi menjadi rewel, gelisah dan susah untuk makan maupun tidur (Liaw et al., 2013; Mitchell et al., 2013; Yin et al., 2015).

Bayi mengalami nyeri karena prosedur invasif, akan memengaruhi perkembangan saraf dan komponen somatosensori dan atau emosional dari respons nyeri di kemudian hari (Garland, 2012). Perubahan faktor biologis (fungsi dan modulasi somatosensori perifer dan sentral, struktur dan konektivitas otak) dan faktor psikososial (misalnya jenis kelamin, gaya koping, suasana hati, respons orang tua) akan memengaruhi respon nyeri pada saat anak-anak dan dewasa muda.

Salah satu upaya penatalaksanaan nonfarmakologi untuk mengurangi nyeri yang dialami oleh bayi baru lahir adalah dengan memberikan tindakan keperawatan yaitu dengan melakukan pembedongan (Erkutt \& Yildiz, 2017). Bedong pada bayi bermanfaat untuk peningkatan perasaan aman, menenangkan, mengurangi refleks kejut dan meningkatkan jam tidur (Abdeyazdan et al., 2016). Pembedongan telah ditemukan sebagai metode yang efektif dalam mengelola stres dan respons nyeri pada bayi baru lahir saat dilakukan prosedur invasif (Mosiman \& Pile, 2013).

Menurut penelitian yang dilakukan Sinpru et al. (2009) bahwa metode bedong adalah metode yang efektif untuk mengurangi nyeri pada bayi yang dilakukan pengambilan sampel darah dengan p-Value $<0,05$. Penelitian Shu et al. (2014) tentang manfaat bedong dan pemanasan tumit terhadap respons nyeri terhadap tumit pada neonatus: didapatkan hasil saturasi oksigen pada kelompok 
bedong lebih tinggi secara signifikan dari pada kelompok penghangat tumit dan skala nyeri dan durasi menangis pada kelompok bedong lebih rendah dari pada kelompok kontrol. Demikian juga dari hasil penelitian Mohammed (2018) menunjukkan bahwa skor nyeri pada kelompok facilitated tucking dan pembedongan kurang dari atau sama dengan 6 pada pemasangan OGT tidak menyebabkan rasa sakit dibandingkan dengan kelompok kontrol ( $p$-Value: 0,00). Membedong bayi baru lahir secara proporsional akan membuat bayi lebih mudah dipegang dan bayi menjadi lebih tenang. Beberapa bayi baru lahir tampak lebih tenang bila mereka dilakukan pembedongan (Hatfield et al., 2018). Penggunaan bedong aman dilakukan untuk mengurangi nyeri pada bayi baru lahir jika dilakukan dengan benar, yakni posisi kaki dan tangan sesuai dengan fisiologis tubuh bayi (fleksi) (L. Fletcher et al., 2018).

\section{METODOLOGI}

Penelitian ini berbentuk kuantitatif dengan design quasi eksperimental, dan rancangan yang digunakan adalah post test with control group design dengan masing - masing kelompok terdiri dari 18 responden. Instrumen yang digunakan untuk pengambilan data adalah lembar observasi nyeri Neonatal Infant Pain Scale (NIPS) yang diadaptasi dari Wong et al. (2009) dan kamera video untuk merekam parameter respons bayi yang dilakukan tindakan invasif pengambilan darah.

Variabel independen dalam penelitian ini yaitu pengaruh pembedongan, variabel independen yaitu penurunan tingkat nyeri.
Cara pengambilan sampel pada penelitian ini adalah dengan menggunakan teknik purposive sampling. Kriteria inklusi diantaranya Usia bayi 4 hari, lahir caesar yang masih dirawat gabung, nadi, respirasi, serta suhu dalam kondisi stabil, tidak ada gangguan pencernaan pada bayi lahir matur dengan berat badan 2500 gr sampai 4000 gr, tidak ada kelainan atas penyakit yang menyertai. Kriteria Eklusi diantaranya: Bayi dengan asfiksia atau ada gangguan pernafasan pada bayi. bayi yang terpasang OGT (orogastric tube) dan bayi berat lahir rendah (BBLR). Bayi mengalami gangguan kongenital. Bayi mengalami gangguan kardiovaskuler. Uji Mann Whitney untuk mengetahui perbedaan sesudah diberikan intervensi antara kelompok kontrol dan kelompok intervensi dengan kemaknaan $\mathrm{p}>$ 0,05 (Dahlan, 2010). Penelitian ini dilakukan dengan melakukan pembedongan pada kelompok intervensi, yang dilakukan dalam waktu 2 menit sebelum pengambilan darah (Dezhdar et al., 2016).Erkut \& Yildiz, 2017) Pada saat diambil darah, peneliti melakukan observasi skala dengan melakukan skala NIPS (Neonatal Infant Pain Scale). Penelitian ini telah dilakukan uji etk di RSUD Al Ihsan Provinsi Jawa Barat dengan nomor 070/15071 dengan tembusan dari Bagian Pendidikan dan Pelatihan RSUD AL Ihsan Provinsi Jawa Barat.

\section{HASIL}

Hasil analisis distribusi frekuensi karakteristik responden berdasarkan jenis kelamin dan pengalaman dilakukan Tindakan invasif dapat dilihat pada tabel berikut:

\section{Tabel 1. Distribusi Frekuensi Karakteristik Responden Berdasarkan Tingkat Nyeri Pada Bayi yang Dilakukan Tindakan Invasif Ambil Darah (n=36)}

\begin{tabular}{lcccc}
\hline \multirow{2}{*}{ Jenis Kelamin } & \multicolumn{2}{c}{ Kontrol } & \multicolumn{2}{c}{ Intervensi } \\
\cline { 2 - 5 } & Jumlah & \% & Jumlah & \% \\
\hline Laki-laki & 10 & 55,6 & 10 & 55,6 \\
Perempuan & 8 & 44,4 & 8 & 44,4 \\
\hline
\end{tabular}




\begin{tabular}{lcccc}
\hline \multirow{2}{*}{ Jenis Kelamin } & \multicolumn{2}{c}{ Kontrol } & \multicolumn{2}{c}{ Intervensi } \\
\cline { 2 - 5 } & Jumlah & $\mathbf{\%}$ & Jumlah & \% \\
\hline Pernah & 12 & 66,7 & 15 & 83,3 \\
Belum Pernah & 6 & 33,3 & 3 & 16,7 \\
\hline Total & 18 & 100 & 18 & 100 \\
\hline
\end{tabular}

Berdasarkan tabel 1, responden laki-laki lebih banyak pada kelompok intervensi $(55,6 \%)$ dan pada kelompok kontrol $(55,6 \%)$. Sementara itu, responden terbanyak berdasarkan pengalaman dilakukan prosedur invasif pada kelompok yang belum memiliki pengalaman $(83,3 \%)$. Hasil analisis distribusi frekuensi responden berdasarkan tingkat nyeri bayi pada bayi yang dilakukan tindakan invasif dapat dilihat pada tabel berikut.

Tabel 2. Distribusi Frekuensi Karakteristik Responden Berdasarkan Tingkat Nyeri Pada Bayi yang Dilakukan Tindakan Invasif Ambil Darah $(n=36)$

\begin{tabular}{lcccc}
\hline \multirow{2}{*}{ Tingkat Nyeri } & \multicolumn{2}{c}{ Kontrol } & \multicolumn{2}{c}{ Intervensi } \\
\cline { 2 - 5 } & Jumlah & \% & Jumlah & \% \\
\hline Bebas nyeri & 0 & 0 & 5 & 27,8 \\
Nyeri Ringan & 0 & 0 & 9 & 50,0 \\
Nyeri Sedang & 2 & 11,1 & 4 & 22,2 \\
Nyeri Berat & 16 & 88,9 & 0 & 0 \\
\hline Total & 18 & 100 & 18 & 100 \\
\hline
\end{tabular}

Berdasarkan tabel 2, jumlah bayi dengan bebas nyeri pada kelompok kontrol yaitu sebanyak $0 \%$ dan pada kelompok intervensi yaitu sebanyak $27,8 \%$. Nyeri Ringan pada kelompok kontrol yaitu $0 \%$ dan pada kelompok intervensi yaitu sebanyak $50,0 \%$. Nyeri Sedang pada kelompok kontrol yaitu sebanyak 11,1\% kemudian pada kelompok intervensi yaitu sebanyak 22,2\%. Nyeri Berat pada kelompok kontrol yaitu sebanyak 88,9 \% dan pada kelompok intervensi yaitu $0 \%$.

Analisis bivariat memaparkan perbedaan tingkat nyeri pada kelompok perlakuan dan kelompok kontrol. Uji beda menggunakan uji Mann Whitney untuk mengetahui perbedaan sesudah diberikan intervensi pada kelompok perlakuan dan kelompok kontrol. Dari 36 responden yang terlibat dalam penelitian ini, diperoleh data sebagai berikut :

Tabel 3. Distribusi Frekuensi Perbedaan Rata-Rata Skala Nyeri Kelompok Perlakuan dan Kontrol $(n=36)$

\begin{tabular}{llccccc}
\hline & Kelompok & Jumlah & Mean rank & $\begin{array}{c}\text { Sum of } \\
\text { Ranks }\end{array}$ & $\begin{array}{c}\text { Mann } \\
\text { Whitney }\end{array}$ & p-Value \\
\hline \multirow{2}{*}{ Skala Nyeri } & Perlakuan & 18 & 9,72 & 175,00 & 4,000 & 0,000 \\
& Kontrol & 18 & 27,28 & 491,00 & & \\
\hline
\end{tabular}

Berdasarkan tabel 3 menunjukkan bahwa responden pada kelompok intervensi diperoleh mean rank 9,72 sedangkan mean rank pada kelompok kontrol adalah 27,28 lebih tinggi 
dibandingkan kelompok intervensi. Hal ini menunjukkan bahwa tingkat nyeri pada kelompok intervensi lebih rendah dibandingkan kelompok kontrol. Hasil uji statistik dengan uji MannWhitney yang telah dilakukan didapatkan hasil 4,000 dengan p-value $0,000(\alpha=0,05)$ maka $\mathrm{H}_{0}$ ditolak dengan interpretasi terdapat pengaruh pembedongan terhadap penurunan tingkat nyeri pada bayi yang dilakukan tindakan invasif ambil darah.

\section{PEMBAHASAN}

Dalam penelitian ini diketahui kelompok intervensi tidak mengalami nyeri berat (0), sementara pada kelompok kontrol terdapat nyeri berat sebanyak 16 (88,9\%). Metode pembedongan dapat mengurangi rasa sakit pada neonatus saat dilakukan pengambilan sampel darah arteri sama seperti pemberian metode Kangoroo Mother Care (Dezhdar et al., 2016). Hal ini menunjukkan bahwa dengan melakukan pembedongan pada bayi dapat menurunkan skala nyeri, karena ekspresi wajah merupakan suatu indikator yang valid untuk menyatakan nyeri pada bayi. Buonocore dan Bellieni (2008) menyatakan bahwa bayi yang dibedong dengan posisi miring atau terlentang dengan posisi ekstremitas fleksi dapat menurunkan nadi 6-10 menit secara signifikan setelah penusukan, menangis lebih pendek, waktu terbangun lebih singkat serta perubahan status tidur lebih sedikit setelah penusukan.

Membedong bayi baru lahir secara proporsional membuatnya lebih mudah dipegang dan dapat menenangkan bayi yang rewel. Beberapa bayi baru lahir tampak lebih tenang bila mereka dilakukan pembedongan (F. Fletcher et al., 2018). Pembedongan bisa menurunkan tingkat nyeri pada bayi saat dilakukan tindakan invasif ambil darah dan skala NIPS (Neonatal Infant Pain Scale) yang dipilih oleh peneliti karena sistem neurologi belum berkembang sempurna saat bayi dilahirkan. Goodstein, Hauck,
Darnall, Feldman-Winter, dan Moon (2016) bahwa dengan membedong bayi menggunakan kain yang lembut dapat memberikan ruang yang terbatas pada bayi dan sentuhan terus menerus, dimana kondisi ini hampir sama seperti kondisi bayi ketika masih dalam rahim dengan ruang yang terbatas. Membedong bayi akan membuat bayi menjadi lebih fokus, menghentikan gerakangerakan memukul-mukul, mengurangi rewel dan dapat membuat bayi menjadi tenang. Kain yang membedong bayi baru lahir memberikan lingkungan yang menyerupai lingkungan intrauterin. Selain itu, kain bedong membantu mempertahankan posisi alami yang sesuai dengan postur anatomis bayi baru lahir dan mengurangi tingkat stres fisiologis (Ramachandran \& Dutta, 2013).

Berdasarkan penelitian, bahwa terdapat pengaruh pembedongan terhadap skala nyeri pada saat dilakukan tindakan invasif. Penelitian ini serupa dengan penelitian yang dilakukan oleh Erkutt dan Yildiz (2017) bahwa pembedongan akan mengeluarkan energi lebih sedikit. Dalam penelitiannya, Erkutt dan Yildiz (2017) mengatakan bahwa skala nyeri dan tangisan bayi yang dilakukan prosedur invasif dengan dilakukan pembedongan lebih rendah dari pada yang tidak dilakukan pembedongan. Dengan demikian, bayi baru lahir akan mengalami stres lebih rendah selama mandi, mencegah hipotermia dengan membantu regulasi termo, secara positif memengaruhi perkembangan otot dan motorik, memfasilitasi adaptasi bayi baru lahir ke lingkungan luar, mengurangi sindrom kematian bayi mendadak (Sudden Infant Death Syndroms), mengatur nadi dan saturasi oksigen dengan menghilangkan rasa sakit yang disebabkan oleh intervensi invasive (Mosiman \& Pile, 2013; Quraishy, Bowles, \& Moore, 2013).

Penelitian yang dilakukan oleh Ho dan Ho (2012) tentang pengaruh pemebdongan terhadap denyut jantung bayi baru lahir, 
dadapatkan bahwa pada kelompok bayi yang dilakukan pembedongan, nadi tidak meningkat dibandingakan dengan kelompok control pada semua titik waktu yang diukur selama prosedur invasif (sebelum prosedur, selama, segera setelah, dan 2, 4, 6, dan 8 menit setelah prosedur invasif). Sementara itu, dalam penelitian yang dilakukan oleh Erkutt dan Yildiz (2017) tingkat saturasi oksigen setelah prosedur invasif meningkat pada bayi yang baru lahir yang dibedong. Dalam penelitian ini, disimpulkan bahwa bayi baru lahir yang dibedong memiliki fungsi pernapasan yang lebih baik setelah dilakukan prosedur invasif (Shu et al., 2014). Sementara itu, penelitian lain mengungkapkan bahwa pembedongan dapat mengurangi durasi menangis bayi pada saat dilakukan pembedongan. Menangis adalah satu-satunya metode komunikasi pada bayi baru lahir untuk mengekspresikan kebutuhan mereka (Gardner \& Goldson, 2011). Pada penelitian Meek dan Huertas (2012) mengatakan bahwa pembedongan pada bayi baru lahir saat dilakukan prodsedur invasive dapat mengurangi durasi menangis.

\section{SIMPULAN DAN SARAN}

Berdasarkan hasil identifikasi tingkat nyeri, jumlah bayi dengan bebas nyeri pada kelompok kontrol yaitu $0 \%$ sedangkan pada kelompok intervensi yaitu sebanyak 27,8\%, nyeri ringan pada kelompok kontrol yaitu $0 \%$ sedangkan pada kelompok intervensi yaitu sebanyak 50,0\%, nyeri sedang pada kelompok kontrol yaitu sebanyak $11,1 \%$ sedangkan pada kelompok intervensi yaitu sebanyak 22,2\%, nyeri berat pada kelompok kontrol yaitu sebanyak 88,9\% sedangkan pada kelompok intervensi yaitu 0\%. Berdasarkan jumlah bayi pada kelompok kontrol yang pernah mengalami tindakan invasif sebelumnya sebanyak $66,7 \%$, dan pada kelompok intervensi sebanyak 83,3\%. Adapun jumlah pada kelompok kontrol yang belum pernah mengalami tindakan invasif sebelumnya sebanyak 33,3\% dan kelompok intervensi sebanyak 16,7\%. Terdapat pengaruh pembedongan terhadap penurunan tingkat nyeri pada bayi yang dilakukan tindakan invasifambil darah, hasil uji statistik menunjukkan p-value $0,000 \leq(\alpha=0,05)$.

Mempertimbangkan hasil penelitian sebagai acuan dalam terapi non-farmakologi pada bayi yang mendapatkan tindakan invasif untuk meminimalkan nyeri. Hasil dari penelitian ini dapat bermanfaat dalam menambah pengetahuan dan dijadikan Standar Operasional Prosedur (SOP) bagi ruangan kebidanan dengan cara melakukan pembedongan pada bayi saat dilakukan tindakan invasif ambil darah.

\section{DAFTAR PUSTAKA}

Abdeyazdan, Z., Mohammadian-Ghahfarokhi, M., Ghazavi, Z., \& Mohammadizadeh, M. (2016). Effects of nesting and swaddling on the sleep duration of premature infants hospitalized in neonatal intensive care units. [serial online] 2016. Iranian J Nursing Midwifery Res, 21, 552-556.

Ball, J. W., Bindler, R. C., \& Cowen, K. J. (2010). Child health nursing: partnering with chidren\& family (Second). Pearson.

Beheshtipoor, N., Memarizadeh, A., Hashemi, F., Porarian, S., \& Rambod, M. (2014). The effect of kangaroo care on pain and physiological parameters in preterm infants on heel-stick procedure: A randomized controlled crossover study. Galen Medical, 2(4), 157-168.

Buonocore, G., \& Bellieni, C. V. (2008). Neonatal Pain: Suffering, pain and risk of braindamage in the fetus and newborn. Springer-Verlag.

Dahlan, M. S. (2010). Besar Sampel dan Cara pengambilan Sampel dalam Penelitian Kedokteran dan Kesehatan. EGC.

Dezhdar, S., Jahanpour, F., Bakht, F., \& Ostovar, A. 
(2016). The effects of kangaroo mother care and swaddling on venipuncture pain in premature neonates: a randomized clinical trial. Iran Red Crescent Med J, 18(4). https://doi.org/10.5812/ircmj.29649

Erkut, Z., \& Yildiz, S. (2017). The Effect of Swaddling on Pain, Vital Signs, and Crying Duration during Heel Lance in Newborns. Pain Management Nursing, 18(5), 328-336. https://doi.org/10.1016/j. pmn.2017.05.007

Erkutt, Z., \& Yildiz, S. (2017). The Effect of Swaddling on Pain, Vital Signs, and Crying Duration during Heel Lance in Newborns. Pain Management Nursing, 1-9. https:// doi.org/1524-9042/\$36.0

Fletcher, F., Pham, T., Bar. S., L. D., Spinazzola, R., Papaioannou, H., \& Milanaik, R. (2018). No Title. Variation in Neonate Swaddling Techniques Advances in Neonatal Care, oo(00), 1-5.

Fletcher, L., Pham, T., Bar, S., Li, D., Spinazzola, R., Papaioannou, H., \& Milanaik, R. (2018). Variation in Neonate Swaddling Techniques. Advances in Neonatal Care, 18(4), 302-306. https://doi.org/10.1097/ ANC.0000000000000506

Gardner, S. L., \& Goldson, E. (2011). The neonate and the environment: impact on development. In S. L. Gardner, B. S. Carter, M. E. Hines, \& J. A. Hernandez (Eds.), Neonatal intensive care. Mosby Elsevier.

Garland, E. L. (2012). Pain processing in the human nervous system: A selective review of nociceptive and biobehavioral pathways. Primary Care, 39(3), 561-571.

Goodstein, M., Hauck, F., Darnall, R., FeldmanWinter, L., \& Moon, R. (2016). Swaddling is not contraindicated in the newborn period. Perinatology, 36, 160. https://doi. org/10.1038/jp.2015.182

Harrison, D., Larocque, C., \& Bueno, M. (2017).
Sweet Solutions to Reduce Procedural Pain in Neonates: A Meta-analysis. Pediatrics, 139(1).

Hatfield, A., Murphy, N., Karp, K., \& Polomano, C. (2018). A Systematic Review of behavioral and environmental interventions for procedural pain management in preterm infants. Pediatric Nursing, 44, 22-30.

Ho, S., \& Ho, L. (2012). Effects of facilitated swaddling for controlling procedural pain in premature neonates: A ran- domized controlled trial. Pain, 13(4).

Johnston, C., Eernandes, A., \& Campbell-Yeo, M. (2011). Pain in neonates is different. The International Association for the Study of Pain, 152(3). https://doi.org/10.1016/j. pain.2010.10.008

Kenner, C., \& Lott, J. (2014). Comprenhensive neonatal nursing care (Zuccarinim (ed.); 5th ed.). Springer Publisher Company.

Krishnan, L. (2013). Pain relief in neonates. Neonatal Surgery, 2(2), 19-27.

Kusumaningsih, F. S. (2016). Pemberian air susu ibu pada neonatus untuk mengurangi nyeri akibat pengambilan sampel darah. Keperawatan Community of Publishing in Nursing (COPING) NERS.

Liaw, J. J., Yang, L., Lee, C. M., Fan, H. C., Chang, Y. C., \& Cheng, L. P. (2013). Effects of combined use of non-nutritive sucking, oral sucrose, and facilitated tucking on infant behavioural states across heel-stick procedures: A prospective, randomised controlled trial. International Journal of Nursing Studies, 50(7), 883-894.

Meek, J., \& Huertas, A. (2012). Cochrane review: Non- nutritive sucking, kangaroo care and swaddling/facilitated tucking are observed to reduce procedural pain in infants and young children. EvidenceBased Nursing, 15(3), 84-85.

Mitchell, A. J., Yates, C. C., Williams, D. K., Chang, 
J. Y., \& Hall, R. W. (2013). Does daily kangaroo care provide sustained pain and stress relief in preterm infants? NeonatalPerinatal Medicine, 6(1), 45-52.

Mohammed., A. R. A. (2018). Effect of facilitated tucking versus swaddling positions on orogastric tube insertion pain among preterm neonates. IOSR Journal of Nursing and Health Science, 7(5), 75-86.

Mosiman, W., \& Pile, D. (2013). Emerging therapies in pediatric pain management. The Art and Science of Infusion Nursing, 36(2), 98-106.

Pappas, B. E., \& Walker, B. (2010). Neonatal delivery room resuscitation Core curriculum for neonatal intensive care nursing (In M. T. V). Saunders Elsevier.

Quraishy, K., Bowles, S. M., \& Moore, J. (2013). A protocol for swaddled bathing in the neonatal intensive care unit. Newborn and Infant Nursing Reviews, 13, 48-50.

Ramachandran, S., \& Dutta, S. (2013). Early developmental care interventions of preterm very low birth weight infants.
Indian Pediatrics, 50(8), 765-770.

Shu, S. H., Lee, Y. L., Hayter, M., \& Wang, R. H. (2014). Efficacy of swaddling and heel warming on pain response to heel stick in neonates: $\mathrm{A}$ randomised control trial. Clinical Nursing, 23(21-22), 3107-3114.

Sinpru, N., Tilokskulchai, F., Vichitsukon, K., \& Boonyarittipong, P. (2009). The effects of clinical nursing practice guideline for swaddling on pain relief from heelstick in neonates. Nursing Sciences, 27(1), 32-45.

Wong, D. L., Hockenberry-Eaton, M., Wilson, D., Winkelstein, M. L., \& Schwartz, P. (2009). Buku Ajar: Keperawatan Pediatrik. Edisi 6 (6th ed.). EGC.

Yin, T., Yang, L., Lee, T. Y., Li, C. C., Hua, Y. M., \& Liaw, J. J. (2015). Development of atraumatic heelstick procedures by combined treatment with non-nutritive sucking, oral sucrose, and facilitated tucking: A randomised controlled trial. International Journal of Nursing Studies, 52(8), 1288-1299. 